\title{
The Performance of a Solar Updraft Tower for Power Generation - Thermodynamic Modeling and Parametric and Economic analysis
}

\author{
Mostafa M. Gad El-Rab \\ Mechanical Power Engineering Department, Faculty of Engineering, Minoufyia University, Shebin \\ El-Kom, Egypt, \\ (Corresponding author: mostafagadelrab2021@gmail.com)
}

\begin{abstract}
Generating electricity through solar energy has been extended and developed in various forms other than the conventional solar energy power plants. Solar chimney is one of the alternative non-conventional power plants that have captured the attention of researchers, where many research studies were profoundly examined to carry out theoretical, numerical, and experimental results that ameliorate this topic. The present paper concerns a parametric analysis of the performance of a solar updraft tower for power generation in relation with the main affecting parameters: tower height, mass flow rate, solar intensity, pressure, temperature, and concentrator efficiency. The main performance parameters regarded are the ideal and actual powers and efficiency. To proceed, a simple thermodynamic modeling is developed and validated against previous experimental studies. Clear explicit relations among the different parameters are drawn based on the calculations performed. Moreover, an economic study to find the Levelized Cost of Economic LCOE of a model that provides $100 \mathrm{MW}$ output power in Lebanon, in addition to studying the variation of LCOE and payback period according to the chimney's height are performed. Particularly, it is found that a solar chimney of $950 \mathrm{~m}$ height may produce $100 \mathrm{MW}$ with 10 years payback period.
\end{abstract}

Keywords: Solar energy, Power generation, Updraft, Solar chimney, Thermodynamic analysis, Economic Analysis.

\section{Introduction}

Through the last decades, energy demand of the world has expanded constantly because of the speedy growth of the industries, mainly in developing nations. However, consuming fossil fuel power plants has substantial downsides such as global warming and widespread air pollution. So, the clean energy alternatives are highly recommended for power generations [1, 2]. According to energy experts, unconventional energy sources can be used for electric power generation which receives a great attention [3, 4]. Power generating technology grounded by green resources is anticipated widely in different countries, such as solar energy, which is considered as a significant clean and reachable source of renewable energy that performs a noteworthy role in providing electric power, especially in a dry and semi-dry climate $[2,5]$. In the last years, a range of solar technologies were used throughout the world to harvest the sun's energy, a spectacular innovation has been introduced by researchers called -Solar Chimney (SC), which is a solar thermal driven electrical power generation plant that converts the solar thermal energy into electrical power in a complex heat transfer process. The execution of this application is of great significance for the development of new energy resources and the commercialization of power generating systems of this type. SC is a method that may help developing countries to promote the rapid development of the solar hot air-flows power generation [6]. Besides generating electricity, SC is used as a type of passive solar cooling and heating system that can be employed to adjust the temperature of a construction as well as providing ventilation, where it is considered as a sustainable approach for ventilation and building space conditioning in different researches [7]. The basic physical principles of centralized electricity generation with Solar Chimney Power Plants (SCPP's) were described by Haaf et al. [8] in 1982. After the pilot plant in Manzanares had 


\section{Mostafa M. Gad El-Rab “The Performance of a Solar Updraft Tower for Power Generation - Thermodynamic Modeling and Parametric and Economic analysis”}

gone into operation in June 1982, the first experimental results confirmed the main assumptions of the original physical model. Later, on the basis of experimental data from July 1983 to January 1984, a semi-empirical, parametrical model was proposed for predicting the monthly mean electrical power output of the pilot plant as a function of solar irradiation [9]. The model predictions agreed reasonably with the experimental data for the exceptionally dry months July- October 1983, but the model failed to simulate the wet months following heavy rainfall in winter and spring 1984. It was realized, that natural precipitation entering the collector has a fundamental influence on the collector performance via evaporation, plant growth and infrared absorption in the collector air [10]. A refined parametrical model was therefore proposed, which includes at least the long term, seasonally varying effect on rainwater on the plants performance and allows the simulation of large plants in climates similar to the climate in Manzanares [11]. In 2003, Dai et al. [12] studied an SCPP in three sites in China. They concluded that SC in the northwestern regions of China was capable of producing 110-190 $\mathrm{kW}$ electric power. The SCPP collector radius was of $500 \mathrm{~m}$, with $200 \mathrm{~m}$ chimney altitude, besides the location is appropriate for solar radiation compared to the other areas. Studies show that the escalation in chimney's height and collector's diameter, leads to nonlinear increase in power generation.

Several research papers held the geographic study of SCPP, where the location is considered a critical criterion for higher efficiency. Papageorgiou [13] suggested that the middle scope deserts of China are appropriate for an outsized scale application of Solar Chimney Technology. The feasibility study of solar chimney power plants as a clean energy resource in the Mediterranean countries was held, in 2008, by Nizetic et al. [14]. It is noticed that the mid scope deserts of China, Taklamakan, have proper climatic conditions and large areas of empty land for employing SCPP. Chergui et al. [15] conducted a performance analysis approach of a SCPP sited in the southwestern area of Algeria. Results indicated that the produced power by this system is contingent on the height of the tower, the ambient temperature, the solar radiation, and the surface of the collector. Besides, results revealed that the effect of insolation on generating power is much more than the effect of ambient temperature. Passing through the existent art of literature on solar chimney investigations presented above, it is clear that such important solar energy system greatly depends on a wide variety of parameters. However, studies and researches on this system that show explicit relations between thermodynamic operating parameters and main performance parameters of the system using appropriate modeling are still rare. Hence, Solar Chimney systems along with the effect of the different parameters on their performance deserve more investigations to be performed.

\section{Aim and Research Significance}

In this context, the present work concerns a new simplified thermodynamic modeling and a complete parametric study of the system performance to raise practical recommendations. The originality of the work resides in the following points:

- It suggests a simplified modular thermodynamic modeling of updraft tower solar chimney system that permits to perform easily parametric studies with low computational time.

- The material presented is important since the performance of the system is analyzed using an appropriate thermodynamic modeling and parametric analysis.

- This work provides useful modeling and parametric analysis for updraft tower solar chimney community. This advantage will be by using the developed thermodynamic modeling in any study aiming to optimize the performance of solar chimney systems. It also offers the possibility to study the effect of a wide range of parameters on the performance of the system, particularly when it comes to study the feasibility of new concepts.

- The parametric analysis performed provide practical recommendations based on the effect of the tower height, mass flow rate, solar intensity, pressure and temperature, and concentrator efficiency on the ideal and actual powers and efficiency.

\section{Theoretical Background}

A Solar Chimney (SC) is a modern technology that depends on solar energy to generate electricity. This solar thermal power plant employs a combination of solar air collector and central updraft tube to generate a solar induced convective flow that drives pressure staged turbines to generate electricity. SC's main working principle is shown in Figure 1, where temperature difference creates difference in density, which also leads to pressure gradient as well. Pressure difference generates a flow from under the collector to the top of the chimney.

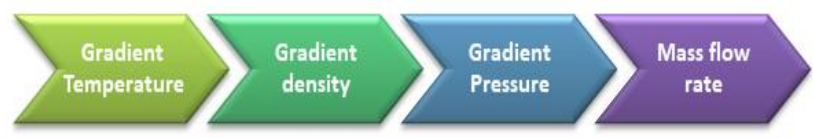

Figure 1- Chimney physical process Solar 


\section{Mostafa M. Gad El-Rab "The Performance of a Solar Updraft Tower for Power Generation - Thermodynamic Modeling and Parametric and Economic analysis”}

SC follows the mentioned physical process, where air is heated up by the greenhouse effect (under the glass collector), which is caused by solar radiation; hot air becomes less dense than the surroundings, thus, it rises up to the chimney at the center of the collector. At the base of the chimney an electricity generating turbine is driven by the rising air as shown in Figure 2.

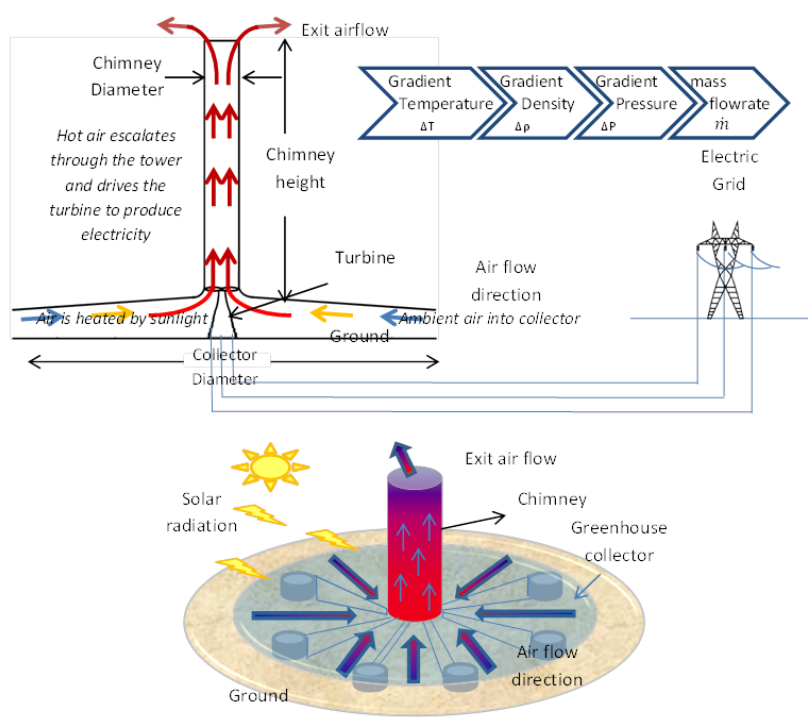

Figure 2- Schematic sketch for power generation solar chimney.

3.1 Basic Components of Solar Chimney Power Plant (SCPP)

- Collector is the crucial part of SCPP. They are the particular type of heat exchangers that converts the solar radiation energy into internal energy [20]. Collectors are utilized to generate hot air between collector and ground surface by greenhouse effect. [21]. Collector is a plastic film or glass plastic film. The collector roof is on a higher level than ground and it is inclined to sidetrack the air on the way to chimney with less resistance. The angle of inclination and material of the collector determine the amount of radiation [16].

- Chimney is one more essential part of the SCPP. The plant's efficiency is governed by the material, structure and the chimney's height and diameter. The chimney is concentric with the roof collector. The chimney builds temperature change at the top and bottom of the tower, which will pull the hot air up outside the chimney. The ascending drive of the hot air operates the turbine positioned at the base of the chimney [16].

- Turbine is a vital piece of SCPP. It is utilized to transform the flow of air into mechanical energy and transfer it to the generator. It is analogous to wind turbine and situated at the bottom of chimney. The speed of air flow causes the turbine to spin which leads the generator to produce electricity into the grid [16].

Power output is interrelated with three main categories that affect the output. Studying these factors carefully and knowing how they affect the power output help in reaching the optimum power of the SCPP. Effects of the main components on obtaining optimum design of solar chimney can be indicated as !

Hot air collector; is obtained by studying the: (1) location, which provides high solar intensity subsequently high temperature, (2) collectors' efficiency that absorbs higher energy, (3) collectors' inclination, (4) diameter, (5) preserving heat under the solar collectors by planting, using PCM and other heat recovery methods.

Chimney ; The optimum power output of the SCPP is highly affected by the chimney's (1) design (straight, sloped, and inclined solar chimney) [8], (2) thickness of the chimney for adiabatic expansion, (3) parameters (height and diameter) that increase the gradient pressure subsequently raising the draft that increase mass flowrate, which drives the Turbine.

Wind turbine; Turbine has a direct effect on the output power, where it transfers the kinetic energy into electrical energy, so it should be studied wisely while choosing the best turbine by considering the (1) efficiency of the turbine that determines the optimum output power. (2) size, (3) availability, (4) reliability, (5) warranty, (6) spare parts availability, (7) proximity of operation and maintenance teams.

\subsection{Applications of Solar Chimney}

Solar Chimney is employed in different countries and shows significant results as presented in Table 1. Different studies have been done on presenting several design parameters of SC in many regions referring to the main model Manzanares, Spain. These studies were done through different strategies finding the relation between the parameters of the chimney and the efficiency of the SCPP, or modeling a design with new parameters as a prototype that could be implemented. As noticed from Table 1, the power production is considerable and related to the size and location of the SCPP.

\section{Thermodynamic modeling and calculation procedure}

Figure 3 can be assumed as a control volume, hence following the first law of thermodynamics, which means, energy or mass can neither be created or 


\section{Mostafa M. Gad El-Rab "The Performance of a Solar Updraft Tower for Power Generation - Thermodynamic Modeling and Parametric and Economic analysis"}

destroyed, but can be converted from one form to another.

Table 1- Solar chimneys in different countries

\begin{tabular}{|l|l|l|l|l|l|}
\hline Year & City & $\begin{array}{l}\text { Chimney } \\
\text { height } \\
(\mathbf{m})\end{array}$ & $\begin{array}{l}\text { Collector } \\
\text { Diameter } \\
(\mathbf{m})\end{array}$ & $\begin{array}{l}\text { Chimney } \\
\text { Diameter } \\
(\mathbf{m})\end{array}$ & $\begin{array}{l}\text { Energy } \\
\text { Power/ } \\
\text { Produc } \\
\text { tion }\end{array}$ \\
\hline $\begin{array}{l}2012 \\
{[17]}\end{array}$ & $\begin{array}{l}\text { cities 12 } \\
\text { in Iran }\end{array}$ & 200 & 244 & 10 & $78 \mathrm{KW}$ \\
\hline $\begin{array}{l}1982 \\
{[18]}\end{array}$ & $\begin{array}{l}\text { Manzana } \\
\text { res, } \\
\text { Spain }\end{array}$ & 195 & 244 & 10 & $50 \mathrm{KW}$ \\
\hline $\begin{array}{l}2010 \\
{[19]}\end{array}$ & $\begin{array}{l}\text {-Qinghai } \\
\text { Tibet } \\
\text { Plateau }\end{array}$ & 1000 & 5650 & 80 & 100 \\
\hline 2009 & $\begin{array}{l}\text { Aqaba in } \\
\text { Jordan }\end{array}$ & 200 & 250 & 10 & $\begin{array}{l}111 \\
\text { KW }\end{array}$ \\
\hline 2001 & UAE & 500 & 1000 & 54 & $8 \mathrm{MW}$ \\
{$[21]$} & & & & & $110-$ \\
\hline 2003 & $\begin{array}{l}\text { Yinchua } \\
\text { n, China }\end{array}$ & 200 & 500 & & \begin{tabular}{l} 
KW \\
\hline 12$]$
\end{tabular} \\
\hline
\end{tabular}

As the solar collectors convert the solar energy into thermal energy, warming up the air trapped under the solar collectors, to create convective heat flow, which is drafted upward to drive the turbine. The main purpose of the thermodynamic analysis is to calculate the output power in terms of the geometric parameters and the heat input ${ }^{\circ}$ produced from the solar irradiance.

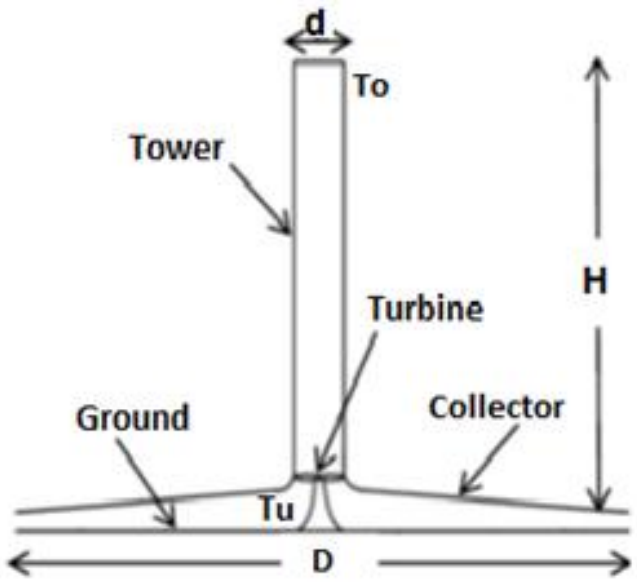

Figure 3- Schematic sketch for power generation SC.

From the theory of fluid mechanics, pressure decreases with height. As well, temperature at the foot is higher than the top. Subsequently, the pressure at the bottom of the tower would be exponentially larger than that at the top of the tower as showed in the equations below.

\subsection{Thermodynamics equations procedure}

- $\quad$ Pressure and temperature distribution inside the tower
The convective heating inside the solar collector takes place while the pressure of the air is kept constant. That means isobaric process is considered.

$\rho_{u} T_{u}=\frac{P_{a}}{R_{s}}=\rho_{o} T_{o}$

From the concept of fluid mechanics, pressure decreases with the altitude and can be represented by;

$\int_{P_{u}}^{P_{0}} \frac{d P}{P}=-\frac{g}{R_{S} T} \int_{0}^{H} d z$

$P_{0}=P_{u} e^{-\frac{g H}{R_{S} T}}=B \cdot P_{u}$

Since; $B=e^{-\frac{g H}{R_{S} T}}$

Ideally, there is no heat loss in this tower, therefore, the reversible adiabatic expansion of the heat transfer fluid between the top and bottom of the tower, can be expressed as follows:

$\frac{T_{o}}{T_{u}}=\left(\frac{P_{0}}{P_{u}}\right)^{\gamma}=B^{\gamma}$

Where: $\gamma=(\mathrm{K}-1) / \mathrm{K}$ and, $\mathrm{K}$ is the isentropic exponent with a value equal to 1.4 .

$\frac{\rho_{0}}{\rho_{u}}=\left(\frac{P_{0}}{P_{u}}\right)^{1-\gamma}=B^{1-\gamma}$

From the theory of statistical thermodynamics, air can be modeled as a perfect gas whose degree of freedom $\approx 5$. Thence; $\mathrm{C}_{\mathrm{p}}=(7 / 2) \mathrm{Rs} ; \mathrm{C}_{\mathrm{v}}=(5 / 2) R_{s}$; $C_{p}=C_{v}+R_{s}$

Where $\mathrm{C}_{\mathrm{p}}, \mathrm{C}_{\mathrm{v}}$, and $\mathrm{R}_{\mathrm{s}}$ are specific heats at constant pressure and volume, and gas constant respectively.

Then, $h_{o}-h_{u}=\frac{7}{2} R_{s}\left(T_{o}-T_{u}\right)$

- Energy Balance of the solar collector

$\dot{Q}=\frac{\pi}{4} D^{2} G \eta_{\text {collector }}=\dot{m} C_{p}\left(T_{o}-T_{u}\right)$

From which the hot temperature under the collector can be computed, thus:

$T_{u}=T_{o}+\frac{\frac{\pi}{4} D^{2} G \eta_{\text {collector }}}{\dot{m} C_{p}}$

- $\quad$ Energy balance at the tower

$\dot{m}\left(h_{u}+g z_{1}+\frac{w_{u}^{2}}{2}\right)=\dot{m}\left(h_{0}+g z_{2}+\frac{w_{0}^{2}}{2}\right)+h_{f}+\dot{P}$

The inlet kinetic energy effect is negligible compared to the outlet because air flow velocity $w_{i} \ll w_{o}$. Therefore;

$-\dot{P}=\dot{m}\left[\frac{7}{2} R_{S}\left(T_{o}-T_{u}\right)+\frac{w_{0}^{2}}{2}+g H+\xi \frac{w_{0}^{2}}{2}\right]$

From which: 


\section{Mostafa M. Gad El-Rab "The Performance of a Solar Updraft Tower for Power Generation - Thermodynamic Modeling and Parametric and Economic analysis”}

$$
\begin{aligned}
& h_{f}=\xi \dot{m} \frac{w_{0}{ }^{2}}{2} \\
& \xi=\lambda \frac{H}{d} \\
& \lambda=\frac{0.3164}{R_{e}^{0.25}} \\
& R_{e}=\frac{\rho \cdot V \cdot d}{\mu} \\
& \dot{m}=\rho_{0} w_{0} A_{0}=\rho_{u} B^{(1-\gamma)} w_{0} A_{0}=\frac{P_{u}}{R_{s} T_{u}} B^{(1-\gamma)} w_{0} A_{0} \\
& \Rightarrow \mathrm{w}_{0}=\frac{\mathrm{R}_{\mathrm{s}}}{\mathrm{P}_{\mathrm{u}} \mathrm{B}^{(1-\gamma)} \mathrm{A}_{0}} \dot{\mathrm{m}} \mathrm{T}_{\mathrm{u}}=\mathrm{Cx} \dot{\mathrm{m}} \mathrm{T}_{\mathrm{u}}
\end{aligned}
$$

Where $C$ is constant given by; $C=\frac{\mathrm{R}_{\mathrm{s}}}{\mathrm{P}_{\mathrm{u}} \mathrm{B}^{(1-\gamma)} \mathrm{A}_{0}}$

Then, $\dot{P}=-\left[\frac{\dot{m}^{3} C^{2} T_{u}^{2}}{2}(1+\xi)+\left(F T_{u}+g H\right) \dot{m}\right]$

$$
\text { So that, } \quad F=\frac{7}{2} R_{s}\left(B^{\gamma}-1\right)
$$

Where $F$ is a negative relationship constant and $\delta$ is an adiabatic constant. The optimum mass flow is at the point where the output power is maximized. Differentiating equation (18) with respect to the mass flow rate yields;

$$
\frac{3}{2} C^{2} T_{u}{ }^{2} \dot{m}^{2}(1+\xi)=-\left(F T_{u}+g H\right)
$$

The maximum mass flow becomes;

$$
\dot{m}_{\max }=\frac{1}{C T_{u}} \sqrt{\frac{-2}{3} \frac{\left(F T_{u}+g H\right)}{(1+\xi)}}
$$

The actual power output of the turbine, becomes:

$$
\dot{\mathrm{P}}_{\mathrm{actual}}=\frac{1}{C T_{u} \sqrt{1+\xi}}\left[\frac{-2}{3}\left(F T_{u}+g H\right)\right]^{\frac{3}{2}}
$$

\section{- Electrical power and efficiency}

The output electrical power depends on the fluid flow power and the efficiencies of the turbine, mechanical shaft and gears, and the generator.

$$
\begin{aligned}
& \dot{\mathrm{P}}_{\text {electrical }}= \\
& \dot{\mathrm{P}}_{\text {actual }} \times \eta_{\text {turbine }} \times \eta_{\text {mechanical }} \times \eta_{\text {generator }}
\end{aligned}
$$

The total efficiency of the system is the ratio of the output power to that of the input power:

$$
\eta_{\text {total }}=\frac{\dot{P}_{\text {out }}}{\dot{P}_{\text {in }}}=\frac{\dot{P}_{\text {electrical }}}{\dot{Q}_{\text {in }}}
$$

\subsection{Flow chart for modeling a SCPP}

Based on previous discussion, two main indices have direct effect on the power output of SC:

1- Location that has a great effect on the power output, where SCPP of approximately same parameters produce different power output due to the different locations, as noticed, same SC model produce a difference of $100 \mathrm{MW}$ when changing the locations from Ardabil to Iranshahr in Iran, due to the high solar irradiation [17].

2- Design Parameters that constitute the SCPP and effect directly on the power output, as the height of the chimney, or the diameter of the collector increase the output power increases, taking into consideration that we are dealing with standard efficiency of solar collector. Consequently, the flow chart in Figure 4 considered the above mentioned direct indices as editable parameters, the power output as the constraint and desired output (D.O.), where the power output should reach the range of desired value set by the user (around or greater than the D.O.), and improving the obtained power output is done by modifying the editable parameters. Hence, the flow chart shows lists of steps required to design SCPP.

The flow chart started by started based on the wellknown model Manzanares, Spain, where the initial parameters are set as the parameters of the model and modifying the direct parameters will be held according to the D.O. If the obtained output power of the model set by the user is less than the output power of Manzanares model, then the user should reconsider the geometrical parameters, which means location, because this indicates that the location is not good enough to give at least the same output of the model. Else, the user can proceed to increase the design parameters, where every time the design parameters are increased the equations mentioned in the thermodynamics modeling and calculation procedure will be recalculated leading to a higher power output, until the D.O. is reached. That's why before starting a design the user should be aware of the location in order to reach higher output with the lower cost.

The user may use any other model and replace it with Manzanares model and do the calculations, the model could be a SCPP built up previously in the same region of the new studied design. Besides, the constraint may be also replaced by another ones 


\section{Mostafa M. Gad El-Rab "The Performance of a Solar Updraft Tower for Power Generation - Thermodynamic Modeling and Parametric and Economic analysis"}

based on the user's standpoint, for example the area or the budget of the SCPP could be the constraint, but of course the equations of the area and LCOE should be added to the solving using equations in the flow chart.

\subsection{Validation against experimental data}

The thermodynamic modeling presented above along with its associated calculation procedure are validated by comparing the output power calculated with the modeling with a published paper done by $\mathrm{Li}$ J. et al. [22], as shown in Figure 5. The parameters of the present modeling were changed to be compatible and compared with the published paper $(d=10 \mathrm{~m}, \mathrm{D}=$ $244 \mathrm{~m}$, and height varies from 200 to $1000 \mathrm{~m}$ ).

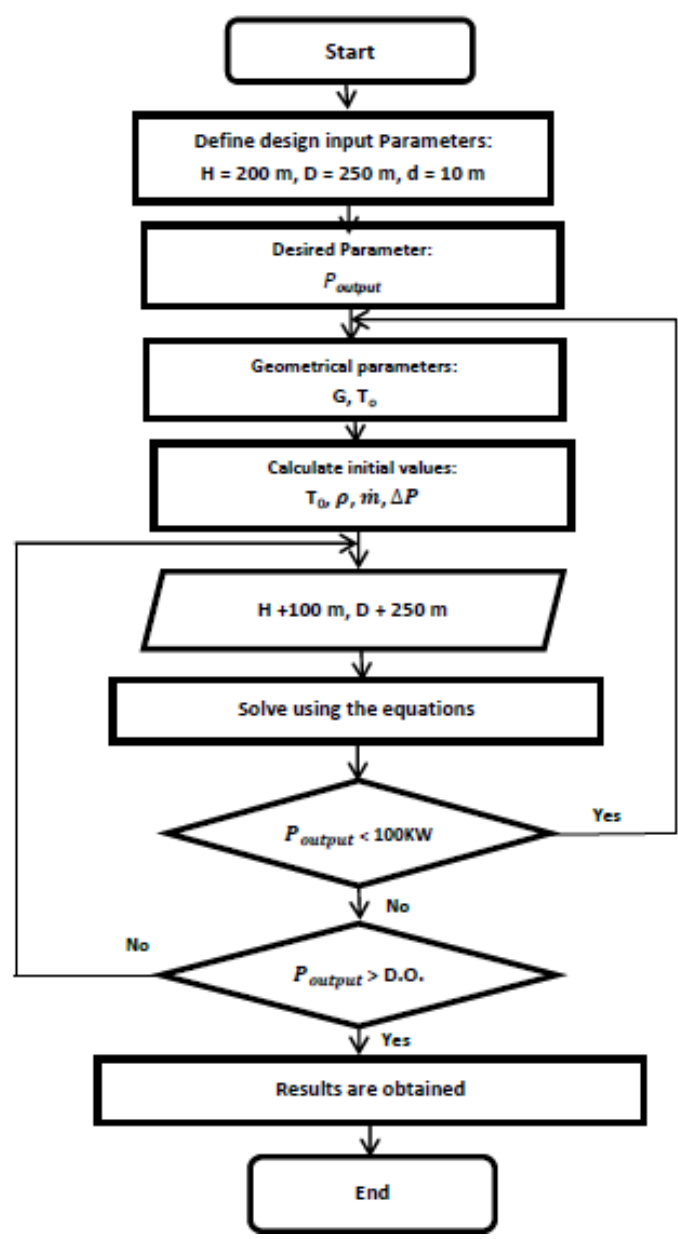

Figure 4- Flowchart for calculating SCPP

As shown in Figure 5, when the chimney height increases, the output power increases almost linearly for both, the model and the experiment. Furthermore, the thermodynamic modeling shows acceptable magnitude orders compared to the experimental data.
As illustration, for a chimney height of $200 \mathrm{~m}$, the output powers of the model and the experiment are 50 $\mathrm{kW}$ and $57 \mathrm{~kW}$ respectively. The error on the power output is then around $13.8 \%$. For a chimney height of $1000 \mathrm{~m}$, the power outputs of the model and the experiment are $285 \mathrm{~kW}$ and $353 \mathrm{~kW}$ respectively and the error is $23.7 \%$. Based on the above comparative results, the thermodynamic modeling and the calculation procedure can be considered accurate enough when it comes to perform parametric and case studies.

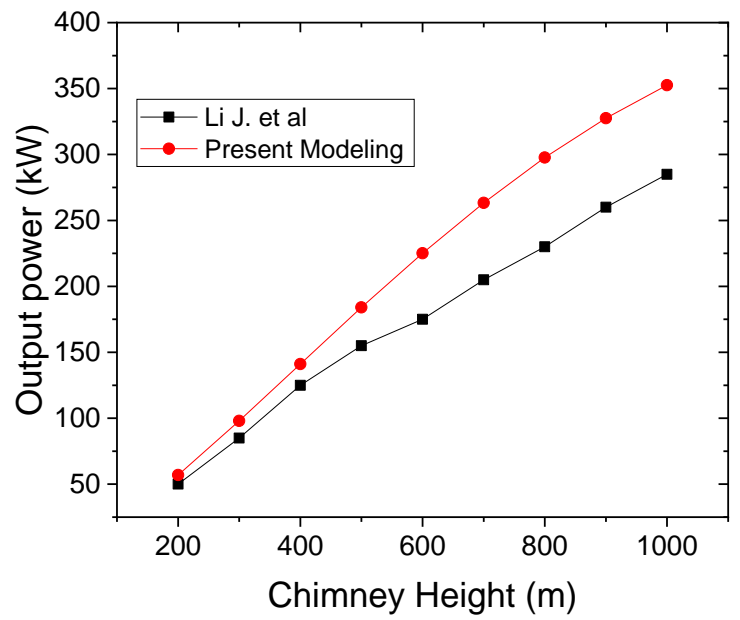

Figure 5-Comparing the power output of the recent paper with Li J. et al. [22]

\section{Parametric analysis results and discussions}

In this section, the thermodynamic modeling presented in the section above is used to study the effect of different operating parameters on other parameters that are related to the performance of the system. The effect of the tower height on the mass flowrate, the effect of the tower height on the electrical power, the variation of actual, ideal and electrical powers, the effect of the solar intensity on the velocities, the effect of the tower height on the pressure and temperature, the variation of ideal and actual powers with respect to mass flow rate, the effect of the concentrator efficiency on the air mass flow rate, and the effect of the tower height on the efficiency will be considered and analyzed in sections 5.1 to 5.8 .

5.1 Effect of the tower height on the mass flowrate Figure 6 shows the variation of the mass flowrate as a function of tower heights during June month in which the solar intensity is at its maximum values 474.69 $\mathrm{W} / \mathrm{m}^{2}$. As noticed from Figure 6 , the mass flowrate increases as the height increases. However, the increase into two approximate linear relation parts; the 


\section{Mostafa M. Gad El-Rab "The Performance of a Solar Updraft Tower for Power Generation - Thermodynamic Modeling and Parametric and Economic analysis”}

first one is when there is a slight increase in mass flowrate with a slope 0.02 . So, as the height increases from $550 \mathrm{~m}$ to $750 \mathrm{~m}$ the mass flowrate increases from $25 \times 10^{4}$ to $28.35 \times 10^{4} \mathrm{Kg} / \mathrm{s}$. In the second part, the slope of the linear relation is 5 times bigger. When the tower height increases from 750 to $1000 \mathrm{~m}$ the mass flowrate increases from $28.65 \times 10^{4}$ to $31.55 \times 10^{4} \mathrm{Kg} / \mathrm{s}$.

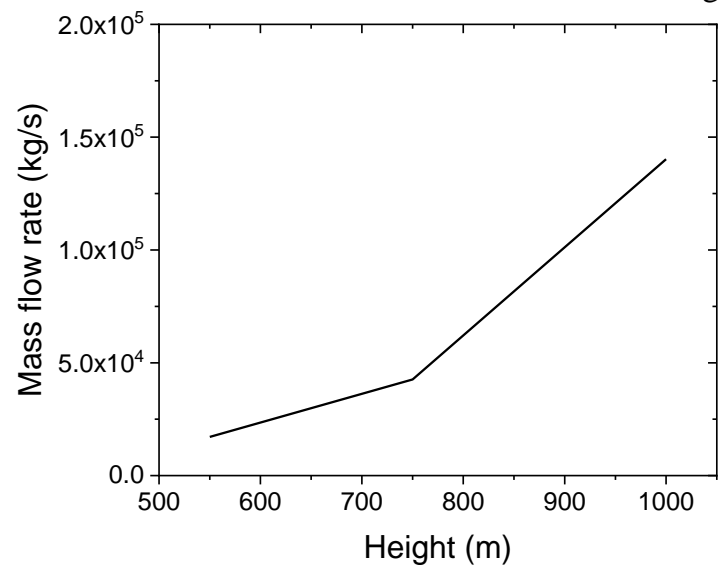

Figure 6- Effect of the tower height on the electrical power

So, there is a critical height, which is $750 \mathrm{~m}$ in our case, at which the rate of change after this critical point is higher compared to the first section $(<750$ $\mathrm{m})$. This could be attributed to the effect of low draft that may occur on smaller heights, on contrast; draft on high heights is higher.

\subsection{Effect of the tower height on the electrical power}

Figure 7 shows the variation of the output electrical power as a function of the tower height during June month in which the solar intensity is at its maximum values $474.69 \mathrm{~W} / \mathrm{m}^{2}$.

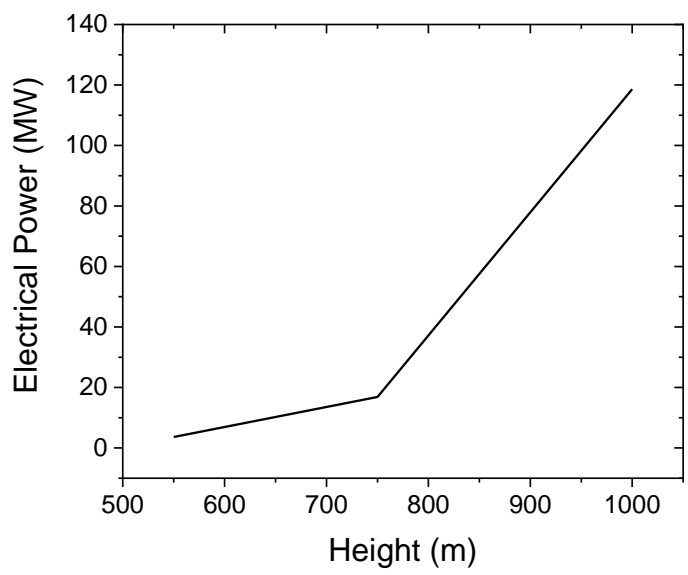

Figure 7- Effect of the tower height on the electrical power
As noticed from Figures 6 and Figure 7, the graphs are so much related, where the electrical output increases as the height increases. However, the increase in electrical power is divided into two approximate linear relation parts; the first one is when there is a slight increase in electrical power with a slope 0.07 . So, as the height increases from $450 \mathrm{~m}$ to $750 \mathrm{~m}$ the electrical power increases from 3.64 to $16.88 \mathrm{MW}$.

\subsection{The variation of actual, ideal and electrical power}

The variation of actual, ideal and electrical power for each month, are presented in Figure 8, where power highly depends on the solar intensity.

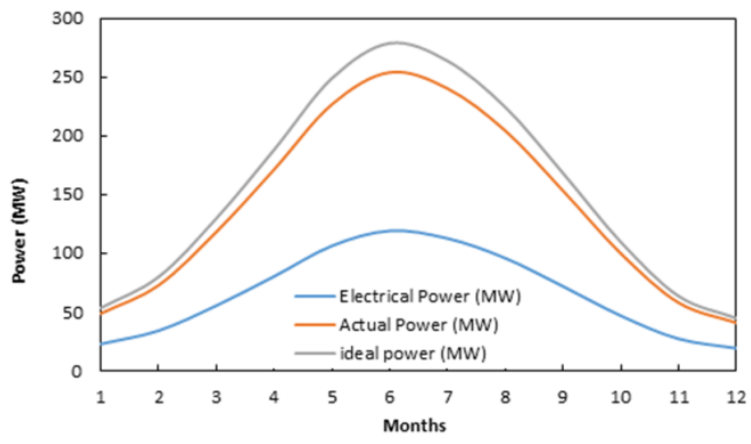

Figure 8- Electrical, Actual, and Ideal power variation through the year

Figure 8 indicates that all the powers highly depend on the solar radiation. The maximum values of the ideal, actual, and electrical powers are registered on June for values of 278.837 MW, 240 MW, and 119 MW respectively. Maximum values of powers are denoted on June due its high solar intensity G. This is attributed to the higher intensity that leads to higher temperature under collector and higher draft due to the increase in gradient pressure that leads to higher power. Lowest powers occur on December: $25 \mathrm{MW}$ for electrical power and $50 \mathrm{MW}$ for ideal power, which provide a power that is 10 times less than the maximum power. Although $25 \mathrm{MW}$ is small amount compared to the maximum power, however it can be useful.

5.4 The effect of the solar intensity on the velocities

The outlet and maximum velocity for each month is presented in Figure 9, to study the relation between both velocities and solar intensity. Figure 9 shows that the variations of both velocities are approximately the same. Besides, it is noticed that the largest values of the maximum and outlet velocities are registered in 


\section{Mostafa M. Gad El-Rab "The Performance of a Solar Updraft Tower for Power Generation - Thermodynamic Modeling and Parametric and Economic analysis"}

June, which are equal to 54.8 and $29.67 \mathrm{~m} / \mathrm{s}$ respectively; this is due to the solar intensity that is recorded on June. This is attributed to the higher $\mathrm{T}_{\mathrm{o}}$ leading to higher $T_{u}$ causing the velocity at the tower to increase.

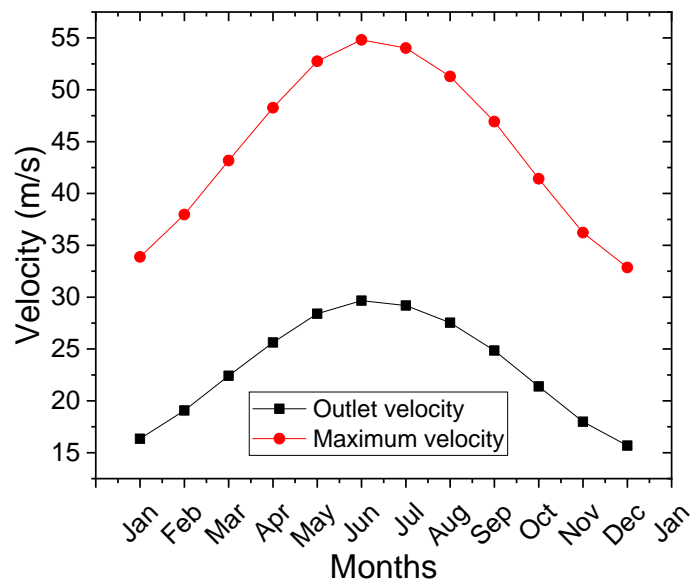

Figure 9- Outlet and maximum velocity variation during the year

This carries the research to a conclusion that the ambient temperature and the velocity inside the tower are prominently related to each other's.

\subsection{The effect of the tower height on the pressure and temperature}

Figure 10 presents the height and pressuretemperature relation, as pressure is an important parameter for creating draft, and temperature increases the mass flowrate as well.

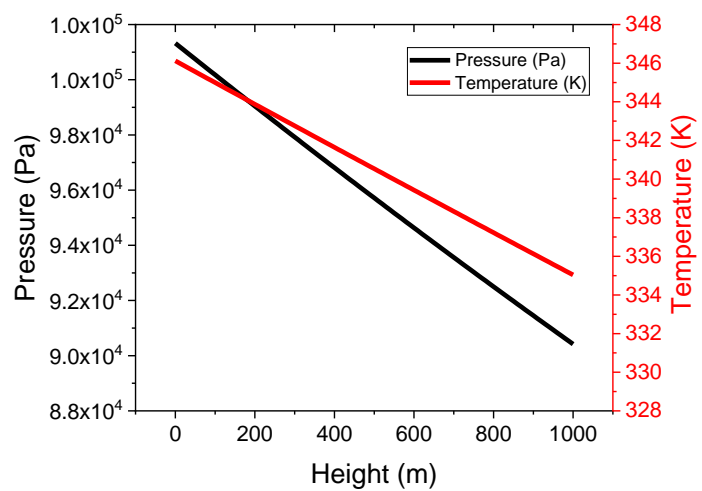

Figure 10- Pressure and Temperature Distribution in the Tower

Figure 10 indicates that the temperature and pressure decreases linearly as the height of the tower increases.
At the base of the tower (where $\mathrm{H}=0$ ), the values of the temperature and pressure are $346.12 \mathrm{~K}$ and $101325 \mathrm{~Pa}$ respectively. When the height increases from $01000 \mathrm{~m}$, the values of both the temperature and pressure decrease to reach $335 \mathrm{~K}$ and $90418.85 \mathrm{~Pa}$, which is expected due to the law of fluid mechanics, which states that pressure decreases with altitude and that there is a relation between pressure and temperature. This difference in pressure helps increasing the draft, the mass flowrate, and justifies the effect of height on the power output. From Figure 10, although the distribution of pressure along the length of the tower is an exponential relationship, this appears only at very high altitudes greater than several thousand meters. But in the current application, in which the altitude does not exceed 1000 meters as a maximum, the changes are very slight and seem linear, whether for pressure, density or temperature. As the greenhouse effect under the collector causes warming the air to slight degrees that do not exceed some degrees, especially at medium solar irradiance, as is the case in Lebanon, which makes the natural draught of air causing relatively medium air velocities

\subsection{Variation of ideal and actual powers with respect to mass flow rate}

The variation of the ideal and actual powers as a function of the mass flow rate along a tower whose height varies from 0 to $1000 \mathrm{~m}$ with diameter of the collector, and diameter of the chimney are taken as 7000 , and $120 \mathrm{~m}$ respectively has been studied in Figure 11 .

From Figure 11, as the height of the chimney increases the mass flowrate increases as a result of high gradient of pressure. Fig. 6 shows that the power output of the chimney is null when the air mass flow is null, and as the mass flowrate increases, the ideal and actual power increases exponentially, reaching maximum ideal and actual powers 277.75 MW and $269.25 \mathrm{MW}$ respectively at $315530 \mathrm{~kg} / \mathrm{s}$ mass flowrate for chimney height $1000 \mathrm{~m}$. The difference, shown in the graph, between the ideal and actual case is due to irreversibilities such as friction loss, heat loss, pressure loss, gravitational loss, head loss and friction factor $h_{f}$. This indicates that the irreversibilities decrease the performance of the turbine. However, the ideal power output is strictly increasing and that is due to the theoretical case that means absence of irreversibilities, which is called head loss and denoted by the factor $h_{f}$. The small difference between the actual and ideal powers is due to the small effect of the irreversibilities, this could be attributed to the high dimensions of the SCPP, 


\section{Mostafa M. Gad El-Rab "The Performance of a Solar Updraft Tower for Power Generation - Thermodynamic Modeling and Parametric and Economic analysis"}

which makes the impediments neglected with respect to the high flow.

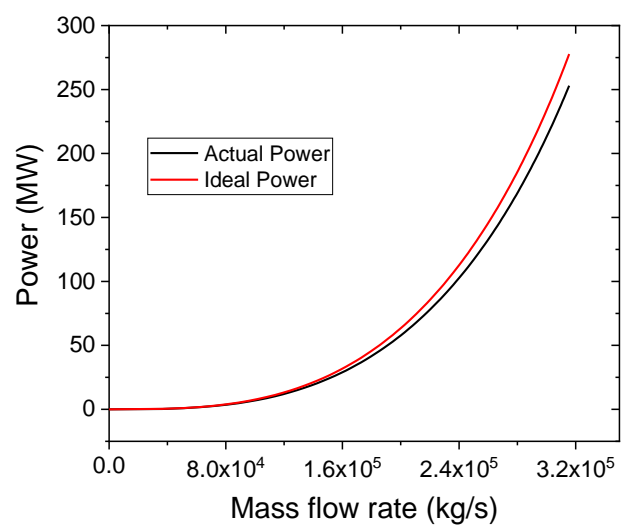

Figure 11- Actual and Ideal Power Variations with respect to Mass Flow Rate

On the other hand, the high values of mass flowrate are due to the large parameters solar chimney diameter of $120 \mathrm{~m}$ and collector diameter of $7000 \mathrm{~m}$.

\subsection{The effect of the concentrator efficiency on the air mass flow rate}

Figure 12 presents the variation of the mass flow rate according to the months for several collector efficiencies.

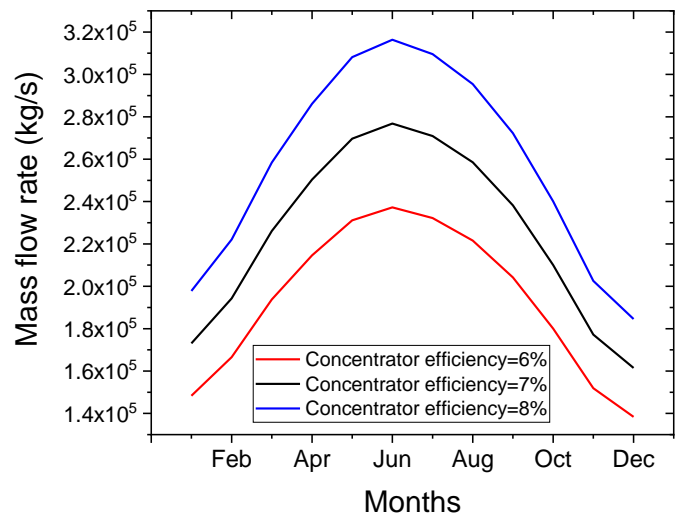

Figure 12- Variation of mass flow rate with different concentrator efficiency

As shown in Figure 12, the mass flow rate is affected by the ambient temperature, which is determined by each month, and thus the mass flowrate upsurges in hot months. This is due to the high temperature that hot months provide. The high temperature raises the thermal energy under collector, subsequently, the mass flowrate will increase. Besides, it is noticed that the efficiency of the collector has a major effect on the mass flowrate, where higher efficiency intensifies the mass flowrate; as a result of higher energy absorbed that upturns the thermal energy to produce higher mass flowrate.

\subsection{Effect of the Tower Height on the Efficiency}

In Figure 13, the plant efficiency is studied against different tower heights.

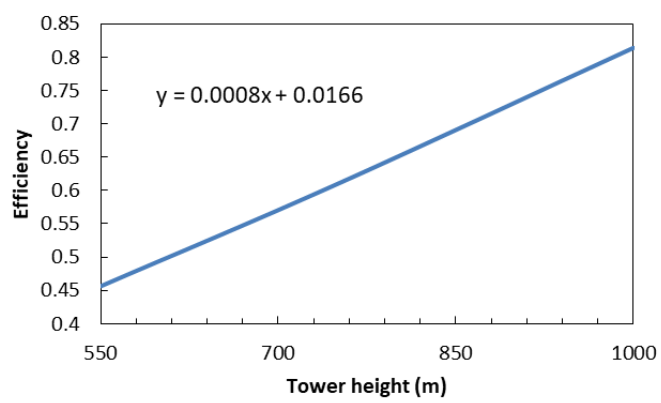

Figure 13- Variation of plant efficiency with tower height

Figure 13 articulates the ascending linear relation between the tower height and the efficiency of the power plant. At minimum height level, the efficiency is minimal, at $1000 \mathrm{~m}$ height the efficiency increases to reach 0.81 . This could be attributed to the higher electrical energy due the increase in height which results in increasing the efficiency. The recent results show that the relation is a straight line and such results agree with Mullet in 1987 [23].

\section{Economic study}

Based on previous studies, the expected life time for a regular SCPP varies from 80 to 120 years [24]. The plant average power of the proposed solar chimney power generation unit in this study is equal to 100 MW with annual total cost. Detailed calculations steps to calculate the Levelized Cost of Economic (LCOE) of the economic study are summarized in Error! Reference source not found. Table 2 shows the basic inputs to computing LCOE, which consist of the sum of the investment, fixed and variable operations and maintenance (O\&M), and fuel costs, by the produced energy over the lifetime of the system. The cost analysis in Table 2 is based on 100 MW SCPP, results obtained are significantly interesting; where the plant has a good net income with an accepted payback period, besides, the fact of being environmental friendly. The LCOE value for this model is 2.35 $\$ / \mathrm{KWh}$ with 10 years payback period, which is 


\section{Mostafa M. Gad El-Rab "The Performance of a Solar Updraft Tower for Power Generation - Thermodynamic Modeling and Parametric and Economic analysis”}

accepted as well especially that it takes into consideration the effect on nature. So, it is worth it to invest in such plant. Figure 14 shows the variations of the LCOE and payback period as a function of the chimney height.

Table 2- Economic study of a $100 \mathrm{MW}$ power output

\begin{tabular}{|c|c|c|}
\hline & Nominal Power & $100 \mathrm{MW}$ \\
\hline a & Total Construction cost & 439.4 \$ Million [25] \\
\hline b & Engineering, test, miscellaneous and indirect cost & $52 \$$ Million [25] \\
\hline c & Total cost, excluding the cost of the land $(a+b)$ & 491.4 S Million \\
\hline d & Annual operation and maintenance cost and other costs & 2.21 \$ Million/year [25] \\
\hline e & Total lifetime cost $(c+d \times 100)$ & 712.4S Million (lifetime 100 years) \\
\hline $\mathrm{f}$ & Production of energy annually $\left(E_{t}\right)$ & $210.5247 \mathrm{GWh}$ \\
\hline g & Electricity cost (c / f x 1000) & $0.0338 \mathrm{~S} / \mathrm{kWh}$ \\
\hline $\mathrm{h}$ & Cost of sold Electricity per year & $7,115,734.86 \$$ \\
\hline $\mathrm{i}$ & Price of $1 \mathrm{kWh}$ to be sold (for a payback period of $10 \mathrm{yrs}$ ) & $0.27775 \mathrm{~S} / \mathrm{kWh}$ \\
\hline $\mathbf{j}$ & Payback period $[\mathrm{c} /(\mathrm{f} \times 1000 \times \mathrm{i}-\mathrm{h})]$ & 10 years \\
\hline $\mathrm{m}$ & $\begin{array}{l}\mathrm{CO} 2 \text { emission during lifetime (from construction to } \\
\text { dismantling) per } \mathrm{kWh}\end{array}$ & $70-170 \mathrm{~g} \mathrm{CO} 2 / \mathrm{kWh}[26]$ \\
\hline $\mathrm{n}$ & Cost $1 \mathrm{Kg}$ of $\mathrm{CO} 2$ emissions & $3.5 \$ /$ ton $[27]$ \\
\hline o & Cost of fuel $\left.F_{t}=\mathrm{f}^{*} 10^{6} \mathrm{KWh}^{*} 3.5^{*} 10^{3} \mathrm{~S} / \mathrm{kg}{ }^{*} 0.1 \mathrm{~kg} / \mathrm{kWh}\right)$ & 736 S Million \\
\hline $\mathrm{r}$ & Lifetime of the system & 80 to 120 years [24] \\
\hline s & Levelized Cost of Economic (LCOE) $(\mathrm{S} / \mathrm{KWh})(\mathrm{r}=6 \%)$ & 2.35 \\
\hline & $\frac{\sum_{t=1}^{n} \frac{\left(I_{t}+M_{t}+F_{t}\right)}{(1+r)^{t}}}{\sum_{t=1}^{n} \frac{E_{t}}{(1+r)^{t}}}=\frac{\sum_{t=1}^{n} \frac{(c+d+0.1 f .1000 \times 3.5)}{(1+0.06)^{t}}}{\sum_{t-1}^{n} \frac{\mathbf{f} \times 1000}{(1+0.06)^{t}}}$ & \\
\hline
\end{tabular}

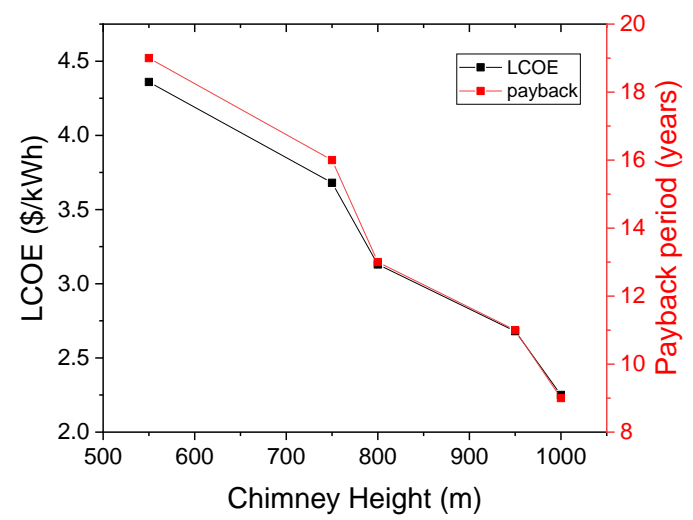

Figure 14- The variation of LCOE and payback period according to the change of chimney's height.

\section{Conclusion and Recommendation}

The present paper exposed a parametric analysis of the performance of a solar updraft tower for power generation in relation with the main affecting parameters: tower height, mass flow rate, solar intensity, pressure, temperature, and concentrator efficiency. The main performance parameters regarded are the ideal and actual powers and efficiency. To proceed, a simple thermodynamic modeling is developed and validated against previous experimental studies. Table 3 shows the relation between the parameters that are studied together and the effect of their growth on the output power.

The main conclusions are as follows:

- The generated power depends on the solar radiation, ambient temperature, height of the tower and collector area.

- Collector efficiency, concentrator efficiency, turbine efficiency and surface roughness inside the chimney are considered as important parameters for higher performance. Thus, the power generation capacity increases with the increase of solar chimney height and solar collector area.

- It is also found that the higher the solar irradiance, the higher the efficiencies of the components and the greater the power generation will be.

- The ambient temperature plays a minor role in affecting power generation for the solar power plant.

- As the tower height increases, the gradient temperatures and pressures between the inlet and outlet of the tower will increase causing the mass flow rate to increase as well.

- The suggested studied model assures a reliable power generation for even small-scale SCs, but solar chimneys with a higher tower produce more power.

- From the above results, designing SCPP in Lebanon is considerable, in which at $950 \mathrm{~m}$ the power output reaches $100 \mathrm{MW}$ with payback period 10 years. The power output can be amplified to become $119 \mathrm{MW}$ at $1000 \mathrm{~m}$ chimney height.

- The performance of this plant can be improved by modifying the tower height, collector area, concentrator efficiency, etc. Also, integrating hybrid heat recovery systems may improve the power plant and provide higher power output.

- The solar updraft tower is a promising technology due to its passive physical principle. In spite of its high investment costs, it is passive green technology that involves no maintenance pension, returns back the cost in short period with significant power output.

- Results show that larger SCPP have shorter payback period and smaller LCOE than smaller SCPP.

\section{Recommendations:}

- SC has no ecological damage and the material used for construction are concrete and glass 


\section{Mostafa M. Gad El-Rab "The Performance of a Solar Updraft Tower for Power Generation - Thermodynamic Modeling and Parametric and Economic analysis"}

which are made up of sand, stone with a selfgenerated energy. Desert areas are an inexhaustible resource of sand and stone for building solar towers and generating electricity. Subsequently, it is recommended, to choose such rightly sustainable source of energy that reproduces itself.

- The combination of hybrid heat recovery and solar is recommended as they result in increasing the efficiency of the solar chimney, for example using the solar collectors as a greenhouse for agriculture maintain thermal energy even after sunsets and improves economic conditions of the country. Also, saving the lost heat at the top of chimney will result in increasing the mass flowrate that increases the efficiency.

- It is recommended to study a combined model of solar chimney and water desalination to be implemented in Sahara desert, where it provided super suitable potentials for an efficient solar chimney power plant, and water desalination process will maintain a humid medium, which increases the efficiency of the solar chimney. Water resource could be Toshka Lakes, which is $503 \mathrm{Km}$ far away from the desert.

- It is recommended to look for large parameters when designing a SCPP, where large SCPP are more efficient and economical than smaller SCPP.
Table 3- The relation between the parameters of solar chimney and the effect of their increase on power output

\begin{tabular}{|c|c|c|c|c|}
\hline & $\begin{array}{c}\text { Parameter } \\
1\end{array}$ & $\begin{array}{c}\text { Parameter } \\
2\end{array}$ & Relation & $\begin{array}{l}\text { Output } \\
\text { Power }\end{array}$ \\
\hline 1 & $\begin{array}{l}\text { Tower } \\
\text { height }\end{array}$ & $\begin{array}{l}\text { Mass } \\
\text { flowrate }\end{array}$ & \multirow{2}{*}{$\begin{array}{l}\text { Positive } \\
\text { linear }\end{array}$} & \multirow{4}{*}{ positive } \\
\hline 2 & $\begin{array}{l}\text { Tower } \\
\text { height }\end{array}$ & $\begin{array}{l}\text { Electrical } \\
\text { power }\end{array}$ & & \\
\hline 3 & $\begin{array}{l}\text { Tower } \\
\text { Height }\end{array}$ & $\begin{array}{l}\text { Pressure } \\
\text { and } \\
\text { Temperatu } \\
\text { re }\end{array}$ & $\begin{array}{l}\text { Negative } \\
\text { linear }\end{array}$ & \\
\hline 4 & $\begin{array}{l}\text { Tower } \\
\text { Height }\end{array}$ & Efficiency & $\begin{array}{l}\text { Positive } \\
\text { linear }\end{array}$ & \\
\hline 5 & $\begin{array}{l}\text { Tower } \\
\text { Height }\end{array}$ & LCOE & \multirow{2}{*}{$\begin{array}{l}\text { Negative } \\
\text { non linear }\end{array}$} & \multirow{2}{*}{ Negative } \\
\hline 6 & $\begin{array}{l}\text { Tower } \\
\text { Height }\end{array}$ & $\begin{array}{l}\text { Payback } \\
\text { period }\end{array}$ & & \\
\hline 7 & $\begin{array}{l}\text { Solar } \\
\text { intensity }\end{array}$ & Velocity & \multirow{3}{*}{$\begin{array}{l}\text { Increasing } \\
\text { then } \\
\text { decreasing }\end{array}$} & \multirow{3}{*}{$\begin{array}{l}\text { June is the } \\
\text { most } \\
\text { positive } \\
\text { month }\end{array}$} \\
\hline 8 & $\begin{array}{l}\text { Actual, ideal, } \\
\text { and } \\
\text { electrical } \\
\text { power }\end{array}$ & Months & & \\
\hline 9 & $\begin{array}{l}\text { Concentrato } \\
\text { r efficiency }\end{array}$ & $\begin{array}{l}\text { Mass } \\
\text { flowrate/m } \\
\text { onth }\end{array}$ & & \\
\hline 10 & $\begin{array}{l}\text { Actual, ideal, } \\
\text { and } \\
\text { electrical } \\
\text { power }\end{array}$ & $\begin{array}{l}\text { Mass } \\
\text { flowrate }\end{array}$ & $\begin{array}{l}\text { Exponenti } \\
\text { al }\end{array}$ & positive \\
\hline
\end{tabular}




\section{Mostafa M. Gad El-Rab "The Performance of a Solar Updraft Tower for Power Generation - Thermodynamic Modeling and Parametric and Economic analysis"}

\section{Nomenclature}

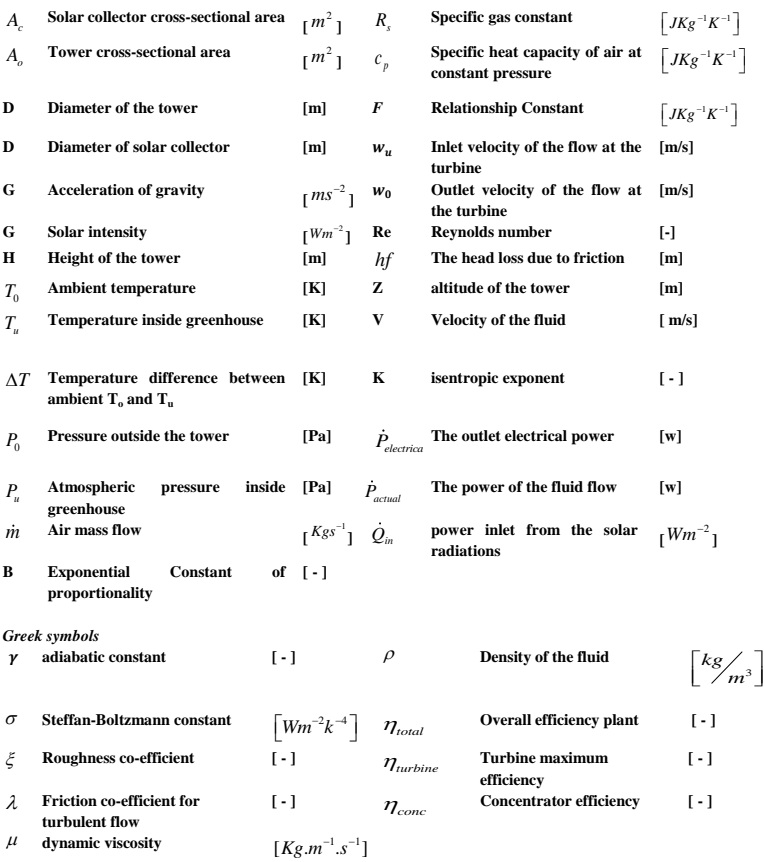

\section{References}

[1] "Advancing Geophysical Assessment for Siting Renewable Energy Facilities," Frontiers in Sustainability, 2021.

[2] RahimiLarki M, Abardeh RH, Rahimzadeh H, Sarlak H. Performance analysis of a laboratoryscale tilted solar chimney system exposed to ambient crosswind. Renewable Energy. 2021 Feb 1;164:1156-70.

[3] Hernandez RR, Jordaan SM, Kaldunski B, Kumar N. Aligning climate change and Sustainable Development Goals with an innovation systems roadmap for renewable power. Frontiers in Sustainability. 2020 Dec $18 ; 1: 11$

[4] Anser MK, Yousaf Z, Zaman K. Green technology acceptance model and green logistics operations:"To see which way the wind is blowing”. Frontiers in Sustainability. 2020 Aug $25 ; 1: 3$.

[5] Hoffacker MK, Hernandez RR. Local Energy: Spatial proximity of energy providers to their power resources. Frontiers in Sustainability.
2020:7.

[6] Chen Y., Yang Y., Wei Y., Jing-Hui Y., Tian Y., "Desert solar chimney power generation technology and its applications," Energy Research and Information, vol. 26, no. 2, p. 117 121., 2010.

[7] Lal S, Kaushik SC, Bhargav PK. Solar chimney: a sustainable approach for ventilation and building space conditioning. International Journal of Development and Sustainability. 2013;2(1):277-9.

[8] Haaf W, Friedrich K, Mayr G, Schlaich J. Solar chimneys part I: principle and construction of the pilot plant in Manzanares. International Journal of Solar Energy. 1983 Jan 1;2(1):3-20.

[9] Pasumarthi N, Sherif SA. Experimental and theoretical performance of a demonstration solar chimney model—Part I: mathematical model development. International Journal of Energy Research. 1998 Mar 10;22(3):277-88.

[10] Terol S., "The present state of research at the solar chimney power plant in Manzanares (Spain) and future prospects for large scale plants," in Proc. International Congress on Renewable Energy Sources, vol. 1, p. 1644, 1987.

[11] Pasumarthi N. and Sherif S. A., "Experimental and theoretical performance of a demonstration solar chimney model-Part II: experimental and theoretical results and economic analysis," International Journal of Energy Research, vol. 22, no. 5 , p. $4,1998$.

[12] Dai YJ, Huang HB, Wang RZ. Case study of solar chimney power plants in Northwestern regions of China. Renewable Energy. $2003 \mathrm{Jul}$ 1;28(8):1295-304.

[13] Papageorgiou C. Floating solar chimney technology: a solar proposal for China. InProceedings of ISES World Congress 2007 (Vol. I-Vol. V) 2008 (pp. 172-176). Springer, Berlin, Heidelberg.

[14] Nizetic S, Ninic N, Klarin B. Analysis and feasibility of implementing solar chimney power plants in the Mediterranean region. Energy. 


\section{Mostafa M. Gad El-Rab "The Performance of a Solar Updraft Tower for Power Generation - Thermodynamic Modeling and Parametric and Economic analysis”}

2008 Nov 1; 33(11):1680-90.

[15] Chergui T, Larbi S, Bouhdjar A. Modelling and simulation of solar chimney power plant performances in southern region of Algeria. In2011 Fourth International Conference on Modeling, Simulation and Applied Optimization 2011 Apr 19 (pp. 1-5). IEEE.

[16] Kavhal NB. A Review Paper on Solar Chimney Power Plant. Int. J. Rec. Innov. Trends Comput. Commun.. 2016;4(1):90-3.

[17] Asnaghi A, Ladjevardi SM. Solar chimney power plant performance in Iran. Renewable and Sustainable Energy Reviews. 2012 Jun 1;16(5): 3383-90.

[18] Cuce E, Cuce PM, Sen H. A thorough performance assessment of solar chimney power plants: Case study for Manzanares. Cleaner Engineering and Technology. 2020 Dec $1 ; 1: 100026$.

[19] Zhou X, Wang F, Fan J, Ochieng RM. Performance of solar chimney power plant in Qinghai-Tibet Plateau. Renewable and Sustainable energy reviews. 2010 Oct 1;14(8): 2249-55.

[20] Abdelsalam E, Kafiah F, Alkasrawi M, Al-Hinti I, Azzam A. Economic study of solar chimney power-water distillation plant (SCPWDP). Energies. 2020 Jan;13(11):2789.

[21] Hamdan MO. Analysis of a solar chimney power plant in the Arabian Gulf region. Renewable Energy. 2011 Oct 1;36(10):2593-8.

[22] Li JY, Guo PH, Wang Y. Effects of collector radius and chimney height on power output of a solar chimney power plant with turbines. Renewable Energy. 2012 Nov 1;47:21-8.

[23] Mullett LB. The solar chimney-overall efficiency, design and performance. International journal of ambient energy. 1987 Jan 1;8(1):35-40.

[24] Okoye CO, Solyalı O, Taylan O. A new economic feasibility approach for solar chimney power plant design. Energy conversion and management. 2016 Oct 15;126:1013-27.

[25] Schlaich JR, Bergermann R, Schiel W, Weinrebe G. Design of commercial solar updraft tower systems - utilization of solar induced convective flows for power generation. J. Sol. Energy Eng.. 2005 Feb 1;127(1):117-24.

[26] Lupi F, Borri C, Kratzig WB, Niemann HJ. Solar Updraft power plant technology: basic concepts and structural design solar. UNESCO Chapter, Encyclopedia Of Life Support Systems. 2008.

[27] "Costs and benefits of carbon offsets," energysage, 6/7/2019. [Online]. https://www.energysage.com/other-cleanoptions/carbon-offsets/costs-and-benefitscarbon-offsets/ 